\title{
Metabolic Reprogramming by In Utero Maternal Benzene Exposure
}

6

7

8
\#Lisa Koshko, \#Lucas K. Debarba, Mikaela Sacla, Juliana M.B. de Lima, Olesya Didyuk, Patrick Fakhoury, "Marianna Sadagurski

\section{*Corresponding author:}

Marianna Sadagurski,

Department of Biological Sciences, Integrative Biosciences Center

Wayne State University

Room 2418 IBio, 6135 Woodward, Detroit, MI 48202

Phone: (313) 5778637

Email: sadagurski@wayne.edu 
bioRxiv preprint doi: https://doi.org/10.1101/2020.10.12.336313; this version posted October 12,2020 . The copyright holder for this preprint (which was not certified by peer review) is the author/funder, who has granted bioRxiv a license to display the preprint in perpetuity. It is made available under aCC-BY-NC-ND 4.0 International license.

\section{Abbreviations:}

39 HFD, high-fat diet; IR, insulin resistance; Type 2 Diabetes, T2DM; volatile organic compounds,

40 VOCs 


\section{Summary}

42 Environmental chemicals play a significant role in the development of metabolic disorders, especially when exposure occurs early in life. We have recently demonstrated that benzene exposure, at concentrations relevant to a cigarette smoke, induces a severe metabolic imbalance in a sex-specific manner affecting male but not female mice. However, the roles of benzene in the development of aberrant metabolic outcomes following gestational exposure, remain largely unexplored. In this study, we exposed pregnant C57BL/6JB dams to benzene at 50 ppm or filtered air for 5 days/week (6h/day from gestational day 1 to birth) and studied male and female offspring metabolic phenotypes in their adult life. While no changes in body weight or body composition were observed between groups, 4-month-old male and female offspring exhibited reduced

51 parameters of energy homeostasis $\left(\mathrm{VO}_{2}, \mathrm{VCO}_{2}\right.$, and heat production). However, only male 52 offspring from benzene-exposed dams were glucose intolerant and insulin resistant at this age.

53 By six months of age, both male and female offspring displayed glucose and insulin intolerance,

54 associated with elevated expression of hepatic gluconeogenesis and inflammatory genes.

55 Additionally, this effect was accompanied by elevated insulin secretion and increased beta-cell

56 mass only in male offspring. Thus, gestational benzene exposure can reprogram offspring for

57 increased susceptibility to the metabolic imbalance in adulthood with differential sensitivity 58 between sexes. 


\section{Introduction}

Type 2 Diabetes (T2DM) is an escalating public health concern with complex genetic, behavioral, and environmental origins (Brancati et al. ; Fujimoto ; Shaw et al. 2010). T2DM mostly results from the interaction between genetic, environmental, and other risk factors (Murea et al. 2012). Emerging evidence suggests that environmental chemical exposures may contribute to T2DM by altering whole-body glucose metabolism, insulin resistance, as well as by affecting satiety signals and energy homeostasis in the central nervous system (Kuo et al. 2013).

67 Compelling evidence indicates that exposure to various toxins or air pollution during sensitive periods of early development causes a predisposition to metabolic disorder later in life (Das et al. 2018; Rauh and Margolis 2016; Soh et al. 2018; Suryadhi et al. 2019; Vanker et al. 2018). Specifically, volatile organic compounds (VOCs) have been shown to induce damaging health Benzene is one of the main VOCs found in ambient air pollution (Kliucininkas et al. 2011). Other sources of benzene include processed foods, occupational exposure, vehicle and manufacturing emissions, cigarette smoke, and electronic cigarette fumes (Duarte-Davidson et al. 2001; Minciullo et al. 2014; Pankow et al. 2017; Salviano Dos Santos et al. 2015; Wallace 1989; Williams and Mani 2015). Benzene is known to be carcinogenic at high concentrations, but its association in causing metabolic diseases particularly

T2DM is still emerging. Recent studies demonstrated that benzene non-cancerous health effects at environmental levels include impaired glucose homeostasis and insulin resistance (Abplanalp et al. 2017; Amin et al. 2018; Debarba et al. 2020). We have recently shown that chronic exposure of adult mice to benzene at the levels relevant to human exposures associated with cigarette smoke $(50 \mathrm{ppm})$ induces severe metabolic imbalance associated with central hypothalamic 
84

85

2020). This data indicates that exposure to benzene can affect an individual's susceptibility to metabolic imbalance and the development of T2DM.

Most epidemiological studies investigating the association between benzene exposure and insulin resistance have focused on young adult or elderly populations living in highly polluted areas (Abplanalp et al. 2017; Burg and Gist 1998; Choi et al. 2014). However, very few studies have assessed the risk of benzene exposure during pregnancy on the long-term metabolic health of the grown offspring. Recent epidemiological studies have highlighted the association of benzene exposure with increased risk for gestational diabetes (Williams et al. 2019). Similarly, epidemiological data have shown a positive association between cigarette smoke exposure in utero and increased risk of obesity and metabolic imbalance in offspring (Behl et al. 2013). A study of traffic pollutants (PM10 and benzene) in a community in northern Italy showed an association between exposure to PM10 and different birth defects (De Donno et al. 2018). However, the direct link between maternal exposure to benzene during pregnancy and metabolic disease in offspring is not clear.

The current study sought to determine whether exposure of pregnant females to benzene alters the susceptibility of the young and/or adult offspring to metabolic imbalance. Pregnant females were exposed to filtered air or concentrations of benzene at the levels relevant to cigarette smoke throughout the gestation by direct inhalation for 6 hours per day, 5 days a week. Under these conditions, benzene exposure had no significant effect on litter size or composition and no significant changes in animals white blood cell counts (Debarba et al. 2020). Our findings indicate that maternal exposure to benzene induces deleterious effects on energy expenditure, glucose metabolism, and insulin resistance in adult offspring in a sex-specific manner, providing the evidence that gestational benzene exposure is a potential risk factor for metabolic disorders. 
108

\section{Methods}

Animals: 8-9 weeks-old male and female C57BL/6 were purchased from The Jackson Laboratory. After a one-week habituation period, female and male mice were mated, and mice were considered pregnant if a vaginal plug was observed. In the present study, we used 5-6 pregnant dams on gestation day 0 (GD0). During the gestational period of 21 days, the pregnant dams were exposed 6 hours per day, 5 days a week to benzene [50 ppm] in the inhalation chamber (see below). Pups were delivered outside of the chamber. Females were fed ad libitum throughout pregnancy and lactation. At the age of 21 days, pups were weaned onto a chow diet (Purina Lab Diet 5001). Most of the presented data related to both male and female mice unless otherwise stated.

Benzene exposure: Pregnant dams in inhalation chambers using FlexStream ${ }^{\mathrm{TM}}$ automated Perm Tube System (KIN-TEK Analytical, Inc) were exposed to benzene concentration of 50 ppm for 6h/day, 5 days a week as before (Debarba et al. 2020). FlexStream ${ }^{\text {TM }}$ automated Perm Tube System allows creating precision gas mixtures. This unit provides a temperaturecontrolled permeation tube oven, dilution flow controls, and front panel touch- screen interface. Mixtures are produced by diluting the miniscule flow emitted from Trace Source ${ }^{\mathrm{TM}}$ permeation tubes with a much larger flow of inert matrix gas, typically nitrogen or zero air. Control dams were breathing regular filtered room air. All mice were provided with water ad libitum and housed in temperature-controlled rooms on a 12-hour/12-hour light-dark cycle.

Metabolic Analysis: Lean and fat body mass were assessed by a Bruker Minispec LF 90II NMR-based device. Intraperitoneal glucose tolerance test (GTT) was performed on mice fasted for 5-6 hours. Animals were then injected intraperitoneally with D-glucose (2 g/kg) and blood glucose levels were measured as before (Sadagurski et al. 2010). For an insulin tolerance test (ITT), animals fasted for 4 hours received an intraperitoneal injection of insulin (Humulin R, $0.8 \mathrm{U} / \mathrm{kg}$ ) diluted in sterile saline. Blood glucose concentrations were measured at the indicated time points. Blood 
insulin levels were determined on serum from tail vein bleed using a Mouse Insulin ELISA kit

134 (Crystal Chem. Inc.). In all tests, tail blood glucose levels were measured at the indicated times

135 after injection. Metabolic measurements of energy homeostasis were obtained using an indirect

136 calorimetry system (PhenoMaster, TSE system, Bad Homburg, Germany). The mice were

137 acclimatized to the cages for 2 days and monitored for 5 days while food and water were provided 138 ad libitum.

RNA extraction and qPCR

140 Total RNA was extracted from the liver with Trizol (Gibco BRL) and $1000 \mathrm{ng}$ of RNA was used for 141 cDNA synthesis using iscript cDNA kit (Bio-Rad Laboratories Inc.). Quantitative real-time PCR was 142 performed using the Applied Biosystems 7500 Real-Time PCR System. The following SYBER 143 Green Gene Expression Assays (Applied Biosystems) were used in this study. See Table 1 for 144 primers sequence. Each PCR reaction was performed in triplicate. Lack of reverse transcription ($145 \mathrm{RT}$ ) was used as a negative control for contaminating DNA detection. Water instead of cDNA was used as a negative control, and the housekeeping gene ß-actin was measured in each cDNA sample. Gene transcripts in each sample were determined by the $\Delta \Delta \mathrm{CT}$ method. For each sample, 148 the threshold cycle (CT) was measured and normalized to the average of the housekeeping gene $149(\Delta C T)$. The fold change of mRNA in the unknown sample relative to the control group was determined by $2-\triangle \triangle C T$. Data are shown as mRNA expression levels relative to the control group. 


\section{Results}

\section{Gestational benzene exposure does not alter body weight in the offspring}

We exposed pregnant females to benzene at the concentration of $50 \mathrm{ppm}$ throughout the pregnancy using an exposure chamber for $6 \mathrm{hr} /$ day, 5 days/wk for 21 days (Debarba et al. 2020). Figure $1 \mathrm{~A}$ illustrates a schematic timeline of the experimental design. This adapted regimen for benzene inhalation resembles chronic human benzene exposure levels in highly polluted gas stations, or exposure to tobacco smoke (De Donno et al. 2018; Lorkiewicz et al. 2019; Pankow et al. 2017). We have recently demonstrated that under these conditions, benzene exposure has no significant changes in white blood cell counts in benzene exposed female offspring were not affected by maternal benzene exposure (Figure 1D and E).

\section{Gestational benzene exposure predisposes to impaired energy expenditure and glucose}

We next assessed whole-body energy homeostasis in young adult male and female

175 significantly decreased oxygen consumption $\left(\mathrm{VO}_{2}\right)$, carbon dioxide $\left(\mathrm{VCO}_{2}\right)$ production and heat

176 production during the $24 \mathrm{~h}$ period $(\mathrm{p}<0.01$, Figure $2 \mathrm{~A}-\mathrm{C}$ and $3 \mathrm{~A}-\mathrm{C})$. Interestingly, male offspring

177 of benzene-exposed dams exhibited a greater reduction in energy expenditure parameters 
180

181

184

185

186

187

188

189

190

191

192

difference in locomotor activity levels or food intake among the groups (Figure 2D, 3D, and data not shown).

Exposure of male mice to benzene during gestation resulted in severe hyperglycemia, as indicated by glucose tolerance test (Figure 4A), and by significantly higher area under the curve (AUC) and HOMA-IR, an index of insulin resistance (Figure $4 \mathrm{~A}, \mathrm{C}$, and D) in 4-month-old male offspring. On the other hand exposure of female mice to benzene during gestation had no effect on glycemia at this age (Figure 4B). However, by six-month of age both male and female offspring of benzene-exposed dams exhibited marked glucose intolerance (Figure 5A and B). By this age male offspring of benzene-exposed dams developed severe insulin resistance $(p<0.05)$, while female offspring, demonstrated a slight impairment in insulin tolerance $(p<0.05$, Figure $5 \mathrm{C}$, and 5D). To examine glucose-stimulated insulin secretion in six-month-old male offspring, we measured plasma insulin at baseline, $15 \mathrm{~min}$, and $30 \mathrm{~min}$ after i.p. glucose challenge (Figure 6A). While insulin fasting levels were not different between the groups, the overall glucose-stimulated insulin secretory response was significantly increased in the male offspring of benzene-exposed dams ( $p<0.05$ vs control offspring). Additionally, maternal benzene exposure modulated islet morphology in these male offspring and they were characterized by a significant increase in $\beta$ cells mass compared to control male offspring (Figure 6B and 6C). Notably, $\beta$-cell mass in female offspring of benzene exposed dams was similar to control female offspring (Supplementary Figure 1), confirming the observed sex differences in metabolic adaptation to benzene exposure (Debarba et al. 2020).

To further investigate the potential mechanisms of metabolic imbalance in benzene exposed offspring, we analyzed the mRNA levels of genes associated with gluconeogenesis, lipid metabolism, and inflammation in the livers from male and female offspring (Figure 7). Strikingly, we observed a significant increase in hepatic inflammatory genes $l k k, T N F a$, and $/ 16$ in both ninemonth-old male and female offspring of benzene-exposed dams, indicating that gestational 
205 benzene exposure induced hepatic inflammation in the offspring (Figure 7A and 7C). Additionally,

206 both male and female offspring exhibited an increase of - C/EBP homologous protein (Chop), a

207 gene involved with the ER-stress pathway (Figure 7A and 7C). We also detected an increase in

208 the expression of genes associated with gluconeogenesis (Pepck and Gck) in livers from benzene

209 exposed offspring as compared to control offspring mice (Figure 7B and 7D). No differences were

210 observed in some additional genes associated with inflammation and ER stress, such as IL1,

211 Emr1, Ire1a, and Xbp1s, or genes associated with lipid and fatty acids synthesis (Supplementary

212 Figure 2). Altogether, these results reveal that benzene exposure during gestation can greatly

213 impair glucose homeostasis and energy balance in adult offspring predisposing them to the

214 development of the metabolic syndrome. 


\section{Discussion}

This study is the first to demonstrate the severe whole-body metabolic imbalance in young adult offspring born to dams exposed to benzene during pregnancy at concentrations relevant to smoking. Metabolic imbalance in offspring was independent of body weight changes and was associated with impaired energy homeostasis and glucose metabolism, affecting both sexes, although the effect was more severe in adult male offspring. Our data provide a link between early-life exposure to an environmental pollutant and the risk for developing metabolic syndrome later in life (in offspring). Further, it allows elucidating some of the risk factors for metabolic syndrome that pose burden at the population level.

Benzene has been listed as an endocrine-disrupting chemical, but its association with the development of childhood metabolic disorders has not been studied in detail, especially when exposure occurs early in life. We show that gestational benzene exposure has no effect on the offspring's body weight or body mass at weaning and up to 40 weeks, however, it is an indicator of insulin resistance and metabolic imbalance in adulthood. Adult male offspring exposed to benzene during gestation developed hyperglycemia and severe insulin resistance followed by

231 increased $\beta$-cell mass and elevated expression of hepatic gluconeogenic genes. The effect of

232 gestational benzene exposure on female offspring metabolic became apparent only by six-months 233 of age, presented by hyperglycemia and mild insulin resistance with normal $\beta$-cell function. Both

234 male and female offspring exhibited a considerable increase in hepatic gene expression 235 associated with inflammation and ER stress. Interestingly, we have recently demonstrated that 236 adult female mice are completely resistant to the negative metabolic consequences of chronic 237 benzene exposure that affects only male mice (Debarba et al. 2020). Benzene crosses the 238 placenta and can be found in the placenta and fetuses immediately following exposure, exerting 239 its effects on developing tissues and cells (Dowty et al. 1976). As such, our data identify gestation 
241 to the toxic effects of gestational benzene exposure. In contrast, the protective sex-specific effects

242 in adult females observed in our recent study may have a hormonal basis (Piazza and Urbanetz

243 2019); however, a causal relationship for these observations remains to be elucidated.

$244 \quad$ Glucose intolerance and insulin resistance displayed in offspring from benzene-exposed

245 dams indicate that maternal benzene exposure has a strong influence on the offspring's glucose

246 metabolism likely by predisposing fetal organs involved in glucose disposal and insulin sensitivity

247 to metabolic imbalance. Insulin secretion following glucose load was significantly higher in insulin-

248 resistant male offspring from benzene exposed dams, suggesting an adaptive $\beta$-cell response to compensate for insulin resistance, which is in line with increased $\beta$-cell mass in these animals.

Interestingly, cigarette smoking during gestation induced changes in $\beta$-cell function including susceptible to oxidative stress-mediated tissue damage (Lenzen et al. 1996). $\beta$-cell hypertrophy and hyperplasia occur during $\beta$-cell compensation to increase $\beta$-cell mass in response to hyperglycemia in diabetogenic states (Cerf et al. 2012). Similarly to insulin resistant and diabetic 257 mice models, increased $\beta$-cell mass in male offspring can be likely attributed to $\beta$-cell hypertrophy 258 and hyperplasia (Jones et al. 2010).

Both male and female offspring from benzene exposed dams exhibited reduced parameters of energy homeostasis, including $\mathrm{O}_{2}, \mathrm{CO}_{2}$, and heat production. These findings suggest that gestational benzene exposure could alter the hypothalamic regulation of energy homeostasis in both sexes (Bouret and Simerly 2004). While nine-month-old male and female offspring display normal body weight, despite reduced energy and heat production, it is 
regulating system is structurally and functionally immature at the start of postnatal life, and the

267 plasticity of the hypothalamic circuitry provides a route by which environmental signals can

268 regulate energy homeostasis (Bouret 2009; 2010). Our recent findings indicate that benzene

269 exposure induces severe hypothalamic inflammation and ER stress in a sex-specific manner

270 (Debarba et al. 2020). Perinatal exposure to persistent organic pollutants (POPs) reduces energy

271 expenditure with an associated increase in body weight in adult female offspring (La Merrill et al.

272 2014). In this regard, various studies have demonstrated the sex-specific effect of perinatal

273 exposure to different pollutants and changes in energy homeostasis in the offspring (Heindel et

274 al. 2017). Further research is needed to address the role of hypothalamic "programming" in

275 response to gestational benzene exposure in both sexes.

Taken together, these data indicate that benzene exposure during gestation is the critical

277 window to induce metabolic syndrome in the adult offspring, where male offspring are more

278 sensitive to metabolic imbalance. Gestational exposure to benzene can interfere with epigenetic

279 programming of gene regulation, thereby influencing the risk of diabetes development later in life.

280 Thorough studies of genome-wide analysis will be needed to understand the epigenetic changes

281 triggered by gestational benzene exposure. Such studies can improve our understanding of the

282 possible maternal factors, underlying the programming of metabolic adversity across the life

283 course of the offspring and identify the critical developmental period during which maternal

284 exposure programs altered metabolic control in the offspring. 


\section{Acknowledgments}

286 The authors thank Madelynn Koch and Li Mao for technical assistance.

287

288

\section{Grants}

290 This project was supported by American Diabetes Association grant \#1-IB-IDF-063, CURES

291 Center Grant (P30 ES020957) and WSU startup funds for MS.

292

293 Disclosure

294 No conflict of interest, financial or otherwise, are declared by the authors. 


\section{Legends:}

297 Figure 1. Gestational benzene exposure does not alter body weight in the offspring. (A)

298 Experimental design timeline. Effect of gestational benzene exposure on body weight gain

299 (g) of males (B) and females (C); fat mass (g), lean mass (g) and total mass (g) of males (D)

and females (E) measured by magnetic resonance imaging (echo MRI), data are expressed as

the mean \pm SEM $(n=6)$. Repeated measures ANOVA were further analyzed with Newman-

302

Keuls post hoc analysis or t-test if necessary to compare between only two groups of the predictor variable.

Figure 2. Gestational benzene exposure impairs energy homeostasis in 4-month-old male

offspring. Effect of gestational benzene on (A) oxygen consumption $\left(\mathrm{VO}_{2}-\mathrm{mL} / \mathrm{kg} / \mathrm{h}\right)$; (B) carbon

Figure 3. Gestational benzene exposure impairs energy homeostasis in 4-month-old 
test if necessary, to compare between only two groups of the predictor variable, $\left({ }^{*}=\right.$ vs control; $\left.{ }^{*} p<0.05 ;{ }^{* *} p<0.01\right)$.

Figure 4. Gestational benzene exposure impairs glucose metabolism in the offspring in a sex-specific manner at 4 months of age. Effect of gestational benzene on glucose tolerance test (GTT) of (A) male and (B) female offspring; (C) Area under the curve (AUC); (D) HOMA - IR of male offspring, at 4 months of age. Data are expressed as the mean \pm SEM $(n=6-7)$. Repeated measures ANOVA were further analyzed with Newman-Keuls post hoc analysis or by t-test if necessary to compare between only two groups of the predictor variable, ( ${ }^{*} p<0.05$ vs control).

Figure 5. Gestational benzene exposure impairs glucose and insulin tolerance in the Keuls post hoc analysis, ( ${ }^{*} p<0.05$ vs control).

Figure 6. Gestational benzene exposure impairs insulin secretion and beta cells mass in male offspring. (A) Insulin secretion; (B) Immunofluorescence staining for insulin (green) and $\left({ }^{*} p<0.05\right.$ vs control). qPCR of hepatic inflammatory and ER stress genes (Ikbkb, Ikbke, TNFa, Il6, CHOP) of (A) males and (C) females. qPCR of hepatic gluconeogenesis genes (PEPCK, Gck) of (B) males and (D) 
bioRxiv preprint doi: https://doi.org/10.1101/2020.10.12.336313; this version posted October 12, 2020. The copyright holder for this preprint (which was not certified by peer review) is the author/funder, who has granted bioRxiv a license to display the preprint in perpetuity. It is made available under aCC-BY-NC-ND 4.0 International license.

345 females. Data were expressed as the mean \pm SEM $(n=4-5)$ and analyzed by t-test $\left({ }^{*}=\right.$ vs control;

$\left.346 \quad{ }^{*} p<0.05,{ }^{* *} p<0.01 ;{ }^{* *} p<0.001\right)$. 


\section{References}

Abplanalp W, DeJarnett N, Riggs DW, Conklin DJ, McCracken JP, Srivastava S, Xie Z, Rai S, Bhatnagar A, O'Toole TE. 2017. Benzene exposure is associated with cardiovascular disease risk. PLoS One. 12(9):e0183602.

Amin MM, Rafiei N, Poursafa P, Ebrahimpour K, Mozafarian N, Shoshtari-Yeganeh B, Hashemi M, Kelishadi R. 2018. Association of benzene exposure with insulin resistance, sod, and mda as markers of oxidative stress in children and adolescents. Environ Sci Pollut Res Int. 25(34):3404634052.

Bahadar H, Maqbool F, Mostafalou S, Baeeri M, Rahimifard M, Navaei-Nigjeh M, Abdollahi M. 2015. Assessment of benzene induced oxidative impairment in rat isolated pancreatic islets and effect on insulin secretion. Environ Toxicol Pharmacol. 39(3):1161-1169.

Behl M, Rao D, Aagaard K, Davidson TL, Levin ED, Slotkin TA, Srinivasan S, Wallinga D, White MF, Walker VR et al. 2013. Evaluation of the association between maternal smoking, childhood obesity, and metabolic disorders: A national toxicology program workshop review. Environ Health Perspect. 121(2):170-180.

Bouret SG. 2009. Early life origins of obesity: Role of hypothalamic programming. J Pediatr Gastroenterol Nutr. 48 Suppl 1:S31-S38.

Bouret SG. 2010. Role of early hormonal and nutritional experiences in shaping feeding behavior and hypothalamic development. J Nutr. 140(3):653-657.

Bouret SG, Simerly RB. 2004. Minireview: Leptin and development of hypothalamic feeding circuits. Endocrinology. 145(6):2621-2626.

Brancati FL, Whelton PK, Kuller LH, Klag MJ. Diabetes mellitus, race, and socioeconomic status. A population-based study [see comments]. Ann Epidemiol 1996 Jan. 6:67-73.

Bruin JE, Kellenberger LD, Gerstein HC, Morrison KM, Holloway AC. 2007. Fetal and neonatal nicotine exposure and postnatal glucose homeostasis: Identifying critical windows of exposure. J Endocrinol. 194(1):171-178.

Burg JR, Gist GL. 1998. The national exposure registry: Analyses of health outcomes from the benzene subregistry. Toxicol Ind Health. 14(3):367-387.

Cerf ME, Chapman CS, Louw J. 2012. High-fat programming of hyperglycemia, hyperinsulinemia, insulin resistance, hyperleptinemia, and altered islet architecture in 3-month-old wistar rats. ISRN Endocrinol. 2012:627270.

Choi YH, Kim JH, Lee BE, Hong YC. 2014. Urinary benzene metabolite and insulin resistance in elderly adults. Sci Total Environ. 482-483:260-268.

Das I, Pedit J, Handa S, Jagger P. 2018. Household air pollution (hap), microenvironment and child health: Strategies for mitigating hap exposure in urban rwanda. Environ Res Lett. 13(4).

De Donno A, De Giorgi M, Bagordo F, Grassi T, Idolo A, Serio F, Ceretti E, Feretti D, Villarini M, Moretti M et al. 2018. Health risk associated with exposure to pm10 and benzene in three italian towns. Int J Environ Res Public Health. 15(8).

Debarba LK, Mulka A, Lima JBM, Didyuk O, Fakhoury P, Koshko L, Awada AA, Zhang K, Klueh U, Sadagurski M. 2020. Acarbose protects from central and peripheral metabolic imbalance induced by benzene exposure. Brain Behav Immun.

Dezest M, Le Bechec M, Chavatte L, Desauziers V, Chaput B, Grolleau JL, Descargues P, Nizard C, Schnebert S, Lacombe $S$ et al. 2017. Oxidative damage and impairment of protein quality control systems in keratinocytes exposed to a volatile organic compounds cocktail. Sci Rep. 7(1):10707.

Dowty BJ, Laseter JL, Storer J. 1976. The transplacental migration and accumulation in blood of volatile organic constituents. Pediatr Res. 10(7):696-701. 
Duarte-Davidson R, Courage C, Rushton L, Levy L. 2001. Benzene in the environment: An assessment of the potential risks to the health of the population. Occup Environ Med. 58(1):2-13. 
years of life: Effect modification by maternal pre-pregnancy bmi. Int J Environ Res Public Health. 15(5).

Suryadhi MAH, Abudureyimu K, Kashima S, Yorifuji T. 2019. Effects of household air pollution from solid fuel use and environmental tobacco smoke on child health outcomes in indonesia. J Occup Environ Med. 61(4):335-339.

Vanker A, Gie RP, Zar HJ. 2018. Early-life exposures to environmental tobacco smoke and indoor air pollution in the drakenstein child health study: Impact on child health. S Afr Med J. 108(2):71-72.

Wallace LA. 1989. Major sources of benzene exposure. Environ Health Perspect. 82:165-169.

Williams AD, Grantz KL, Zhang C, Nobles C, Sherman S, Mendola P. 2019. Ambient volatile organic compounds and racial/ethnic disparities in gestational diabetes mellitus: Are asian/pacific islander women at greater risk? Am J Epidemiol. 188(2):389-397.

Williams PR, Mani A. 2015. Benzene exposures and risk potential for vehicle mechanics from gasoline and petroleum-derived products. J Toxicol Environ Health B Crit Rev. 18(7-8):371-399.

Yoon HI, Hong YC, Cho SH, Kim H, Kim YH, Sohn JR, Kwon M, Park SH, Cho MH, Cheong HK. 2010.

455 Exposure to volatile organic compounds and loss of pulmonary function in the elderly. Eur Respir J. 36(6):1270-1276. 


\section{A}

Pregnant dams exposed to $50 \mathrm{ppm}$ benzene, $6 \mathrm{hr} /$ day
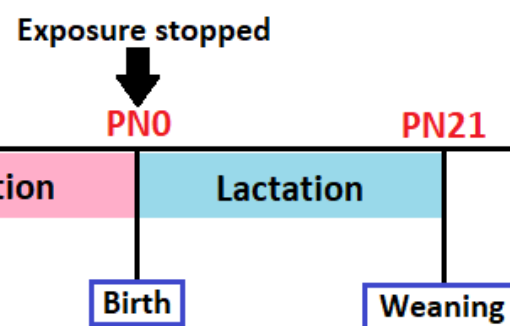

\begin{tabular}{|c|}
\hline Energy \\
$\&$ \\
Glucose \\
Homeostasis \\
Measurements \\
\hline
\end{tabular}
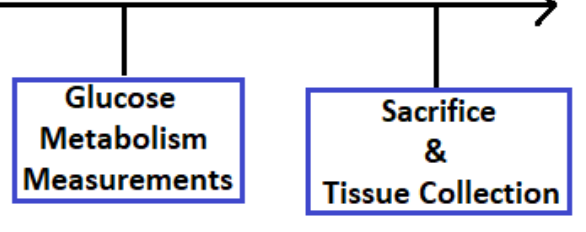

B

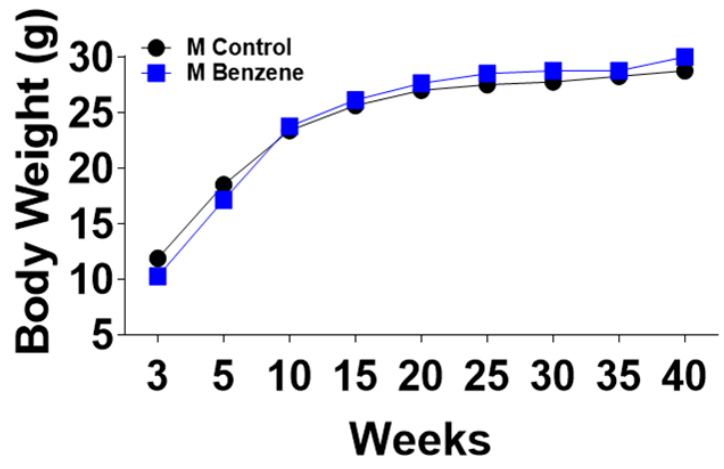

D

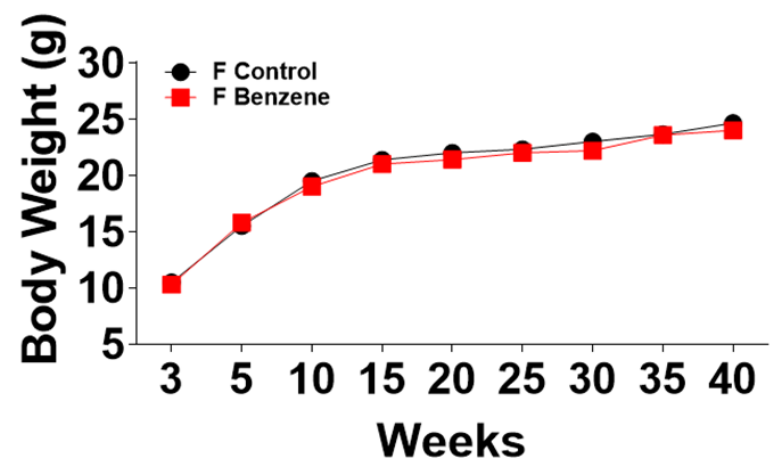

E

Body Composition

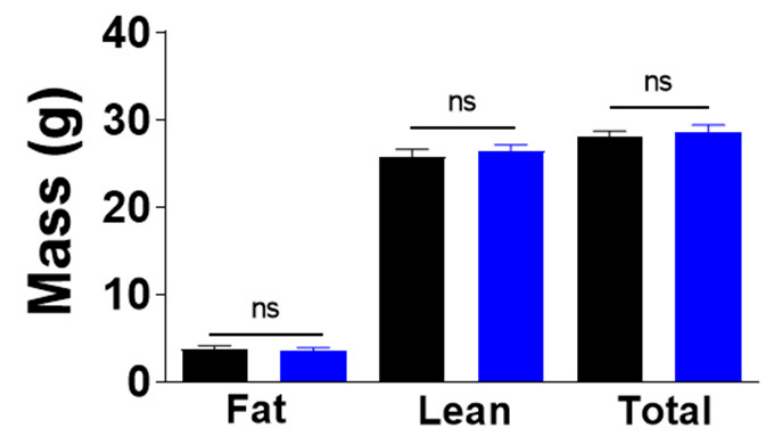

C

Weeks

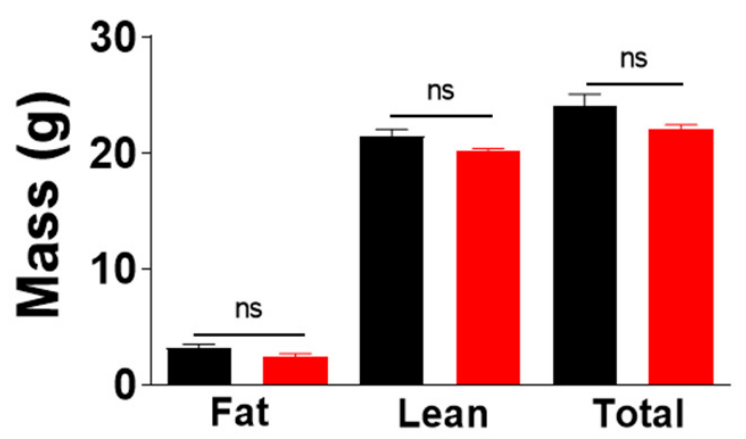

Figure 1 


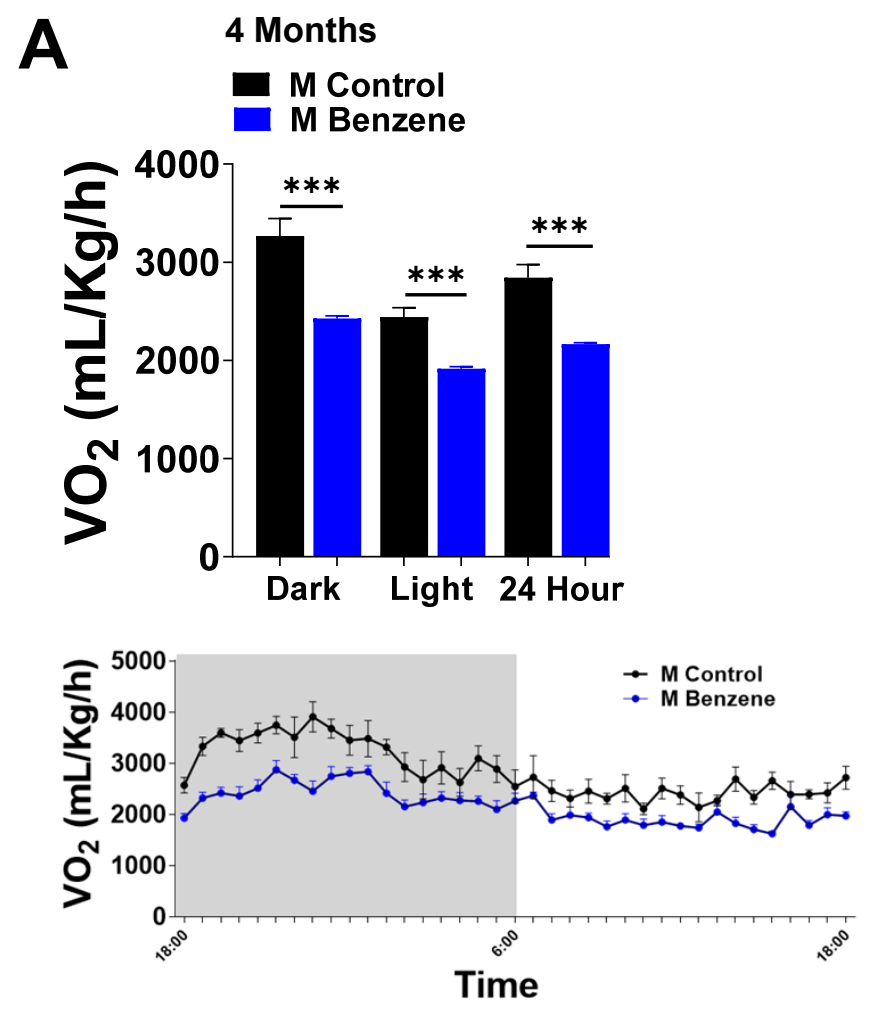

C
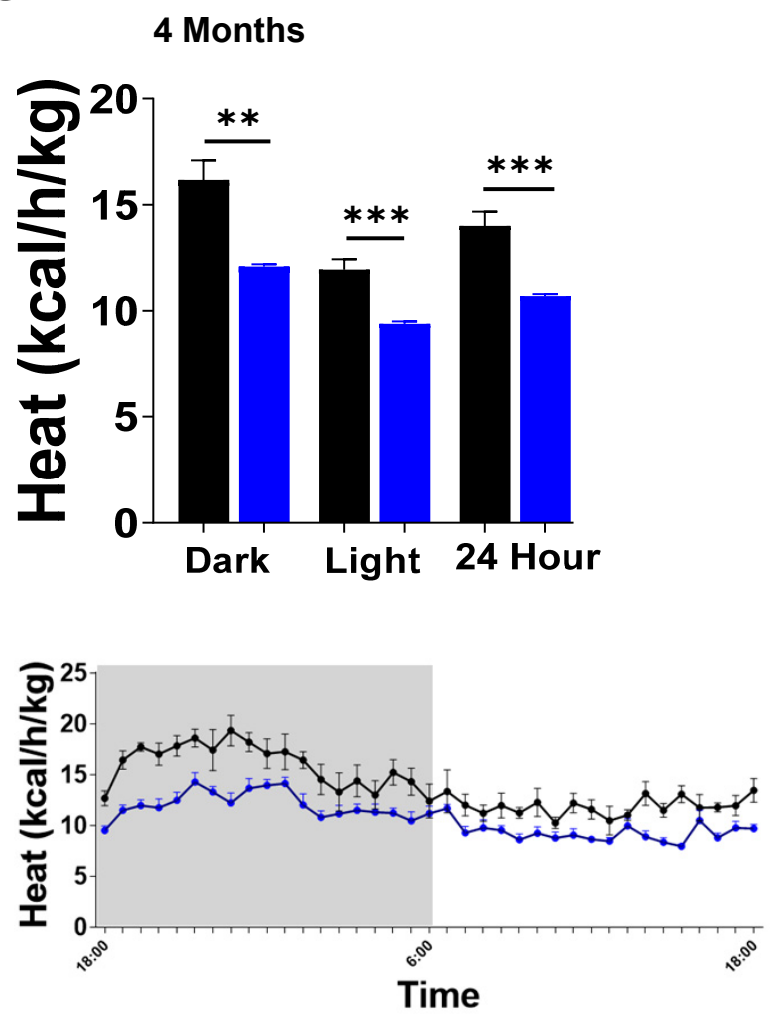

B

4 Months
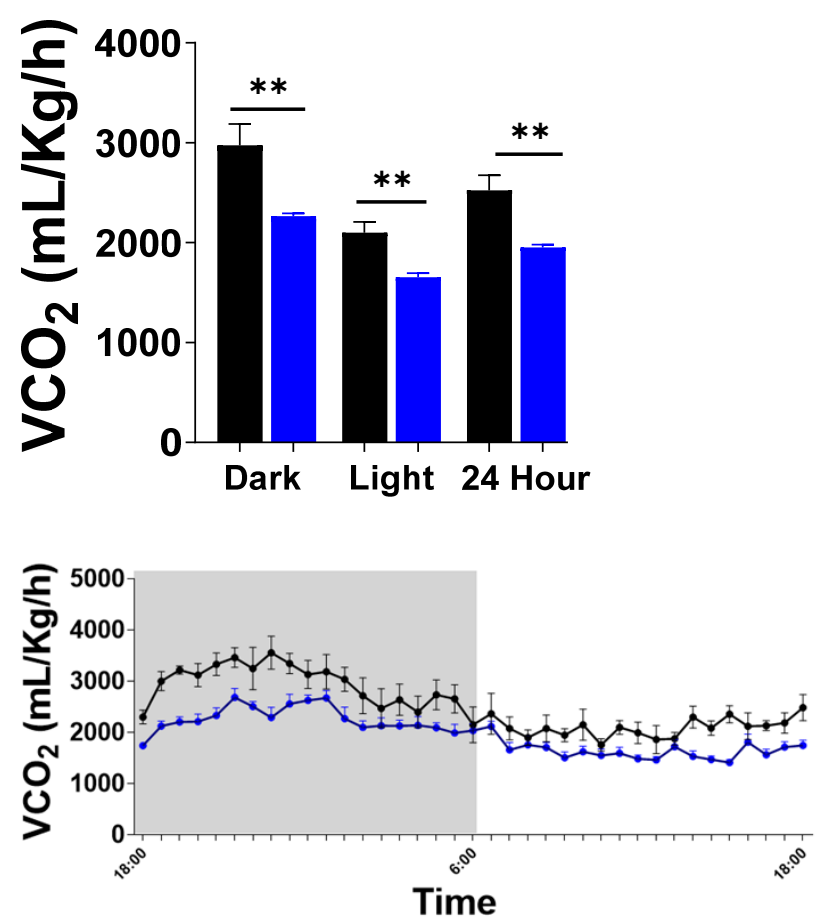

D
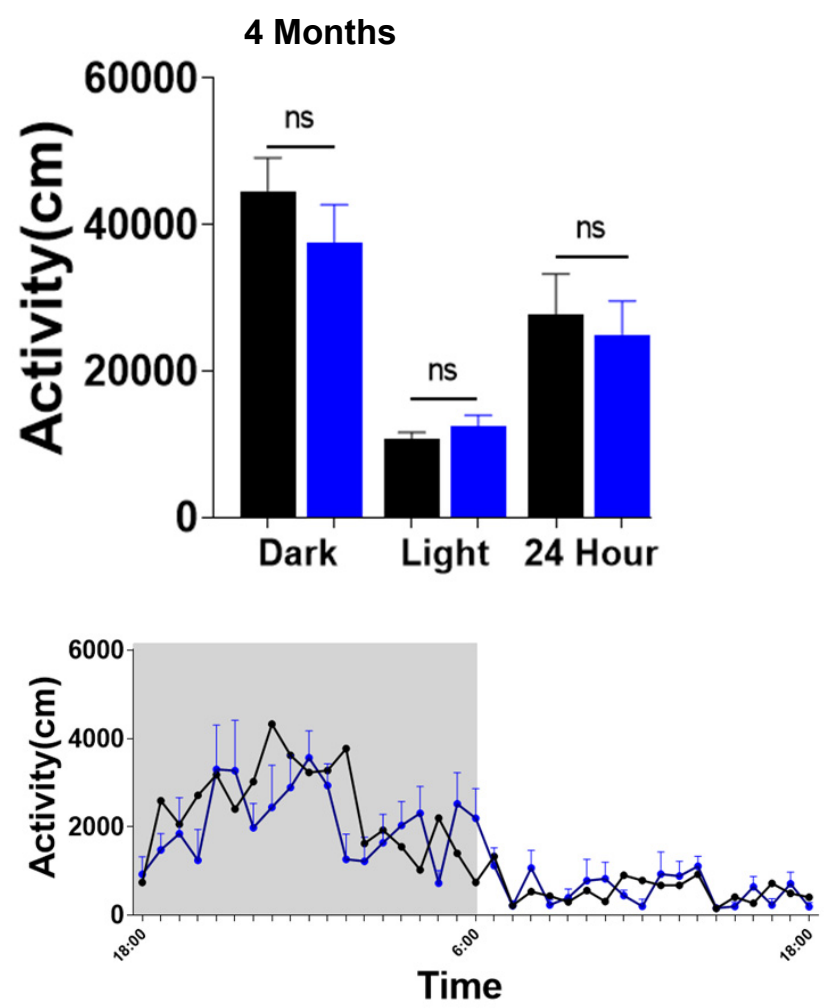

Figure 2 

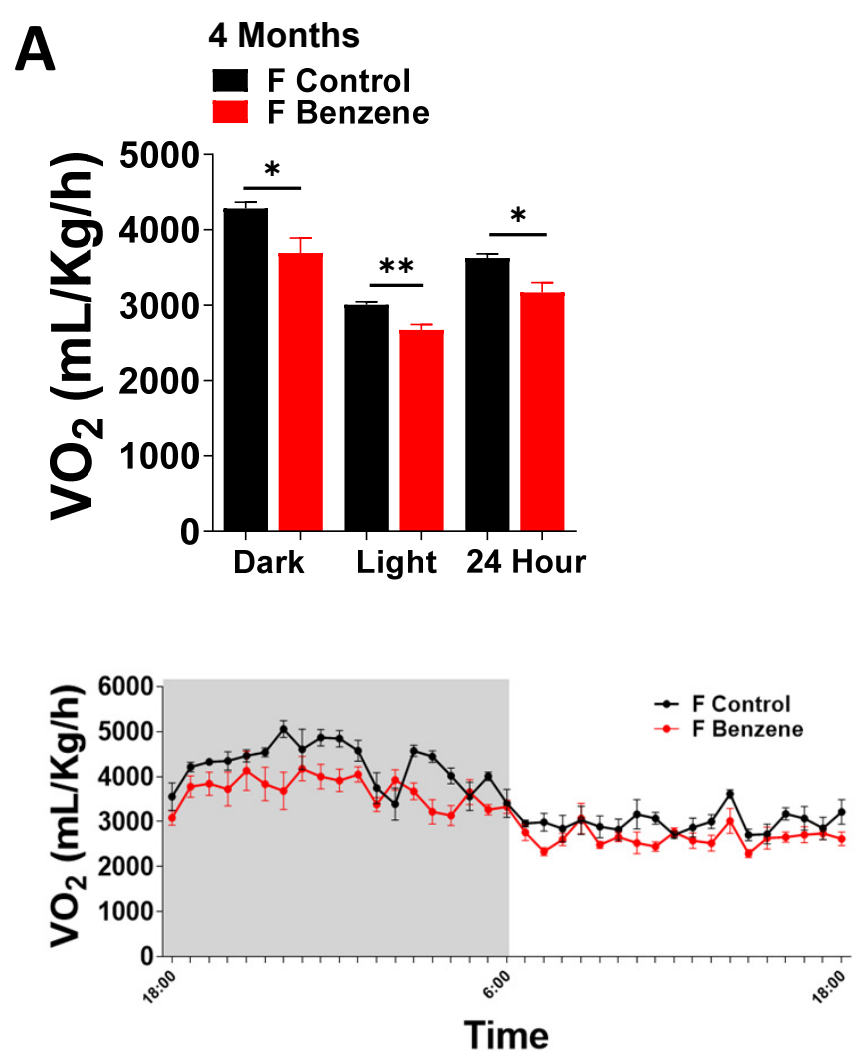

C
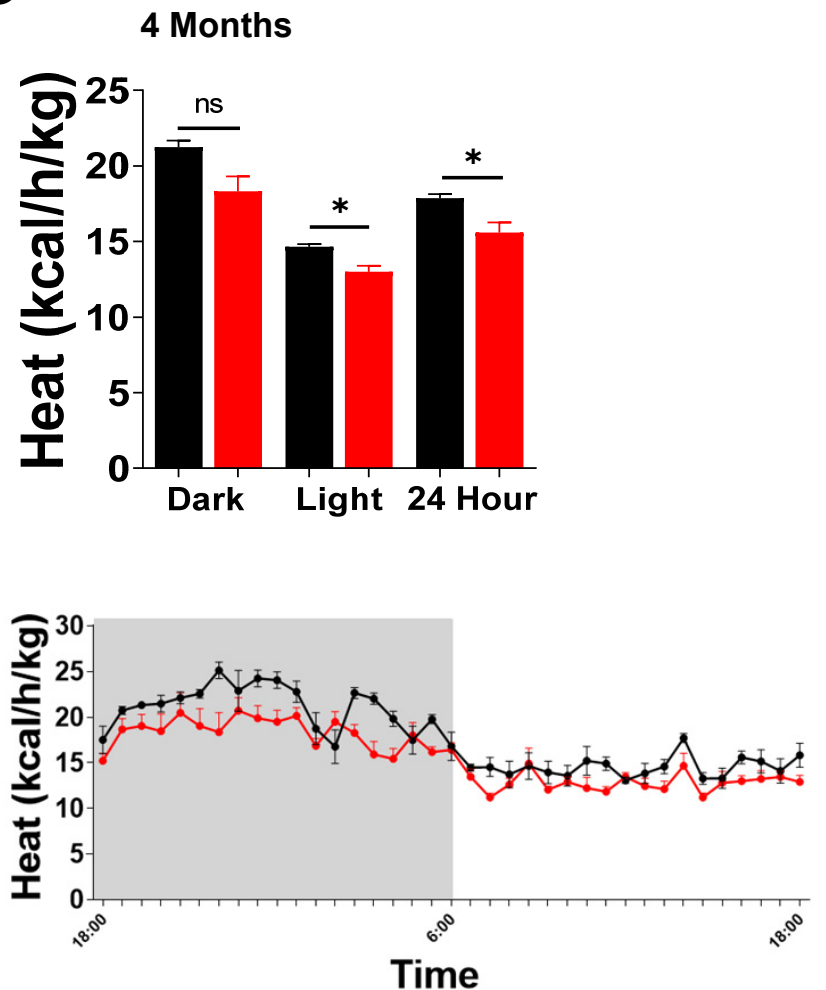

B
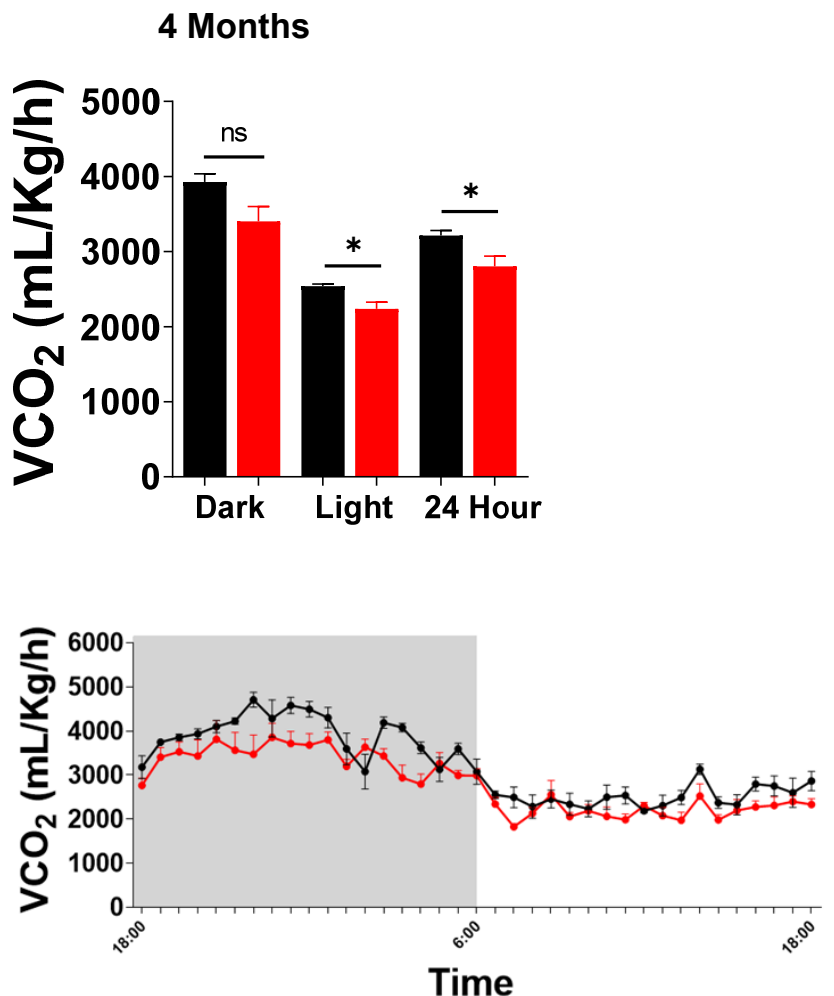

D
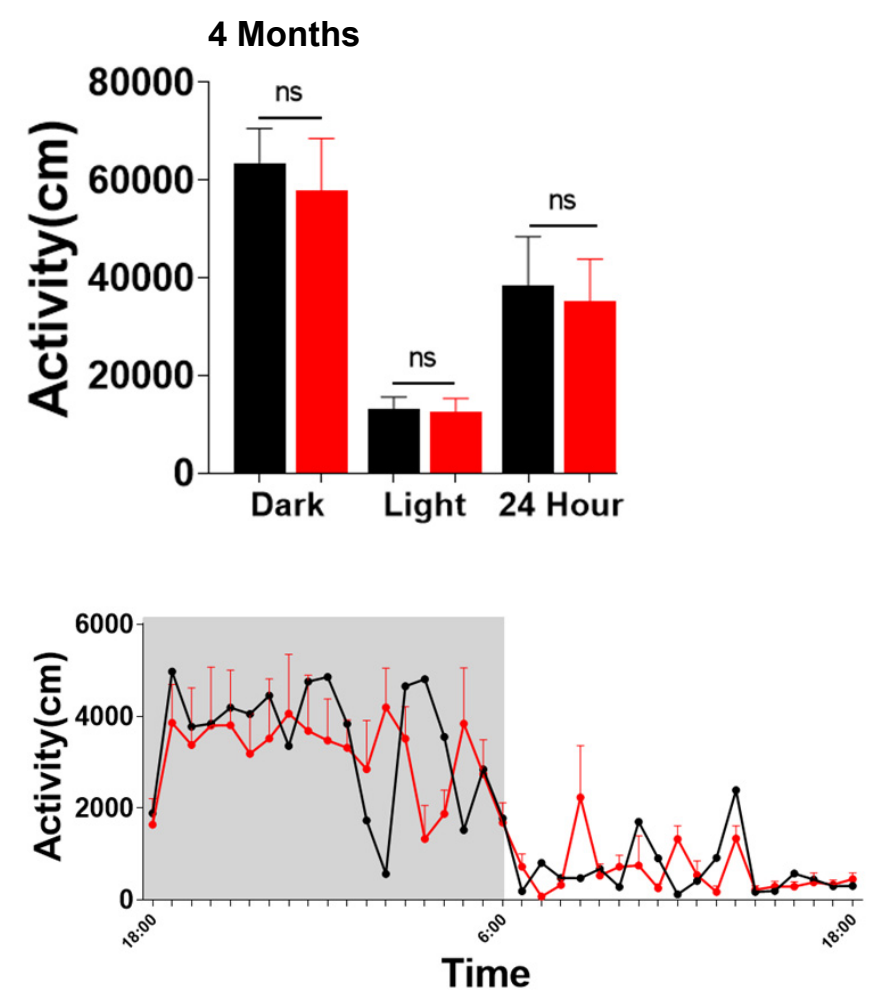

Figure 3 
A

B
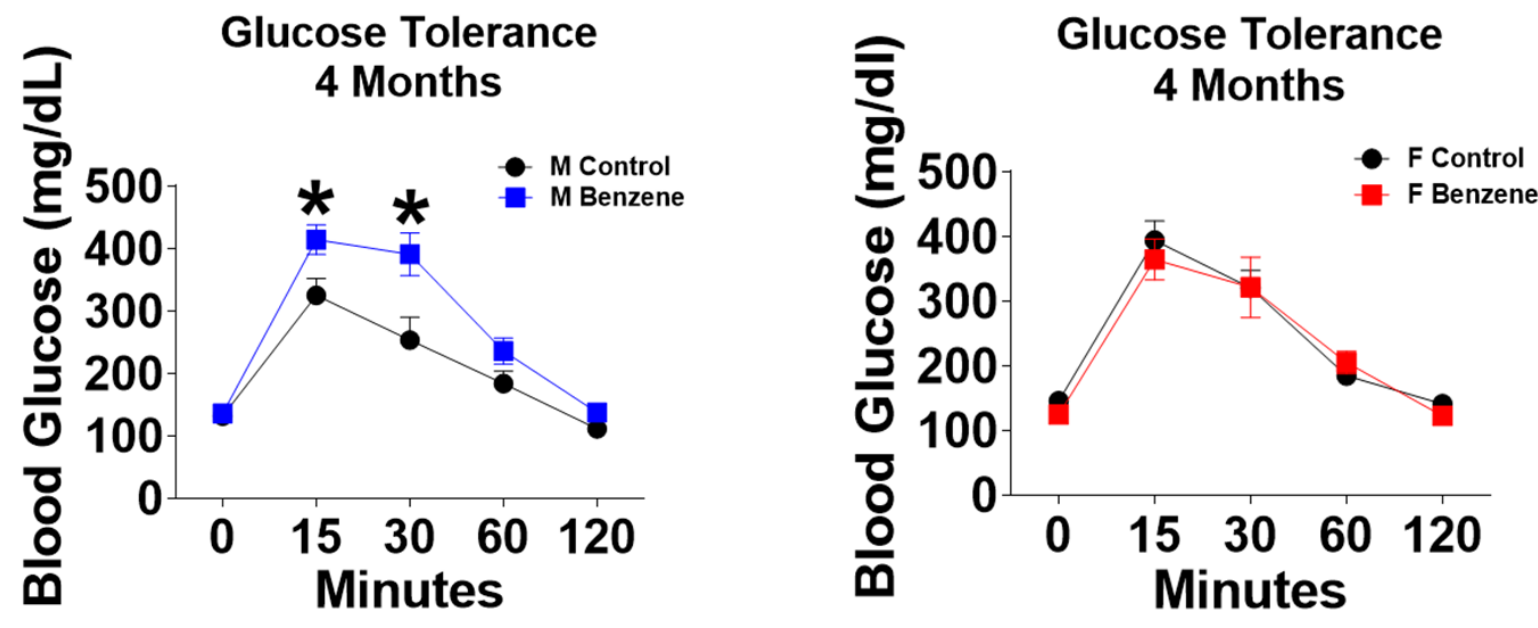

C

D
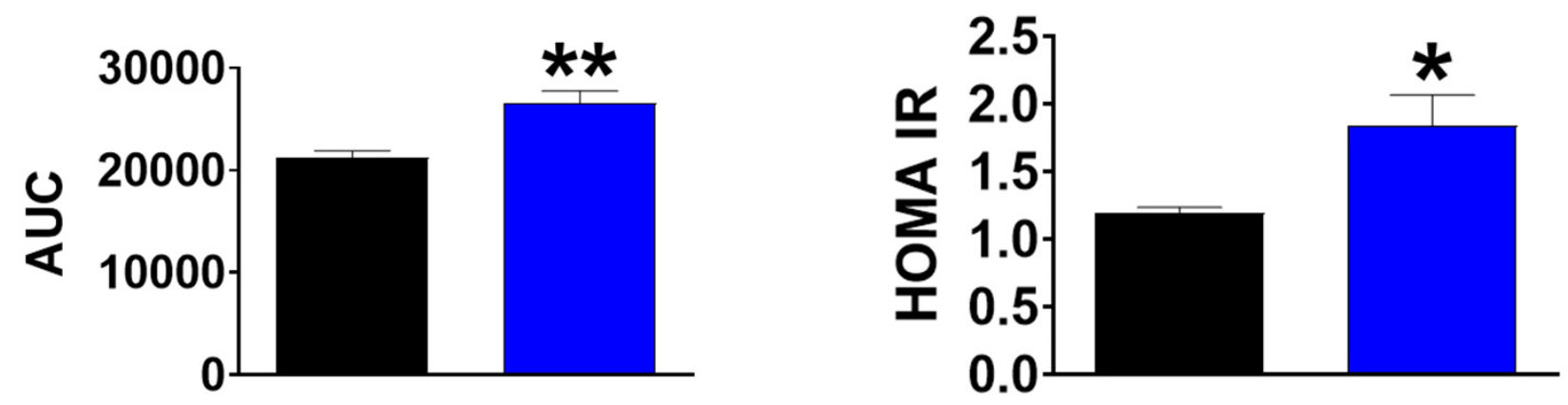
A

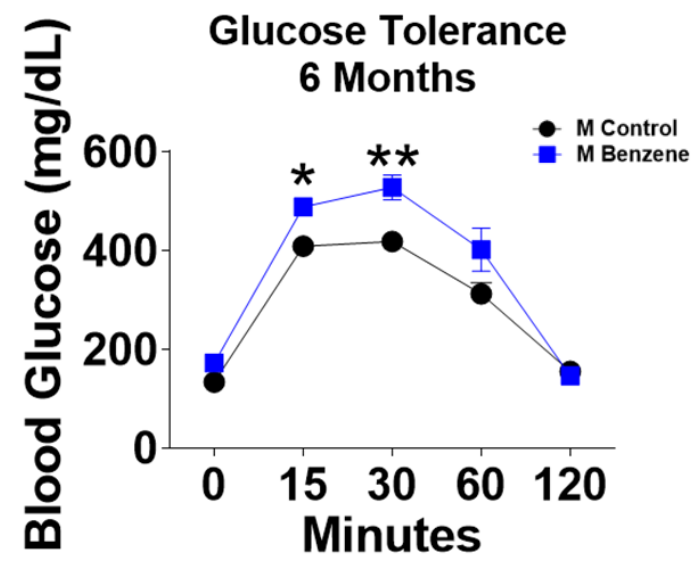

C

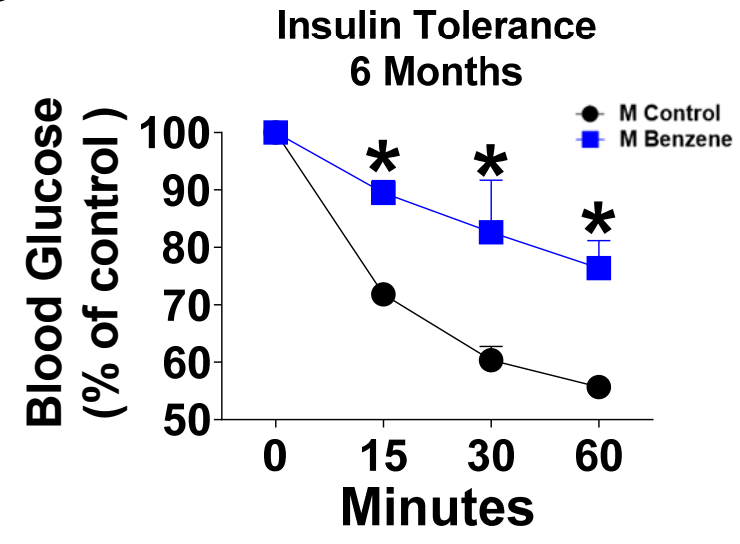

B

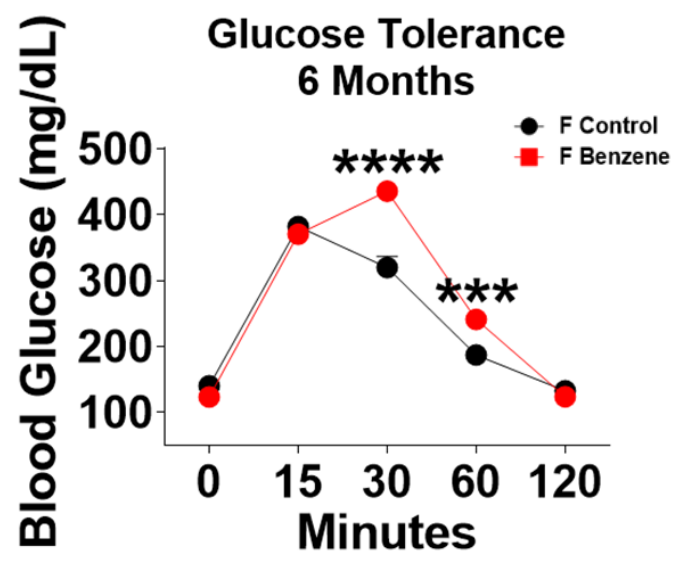

D

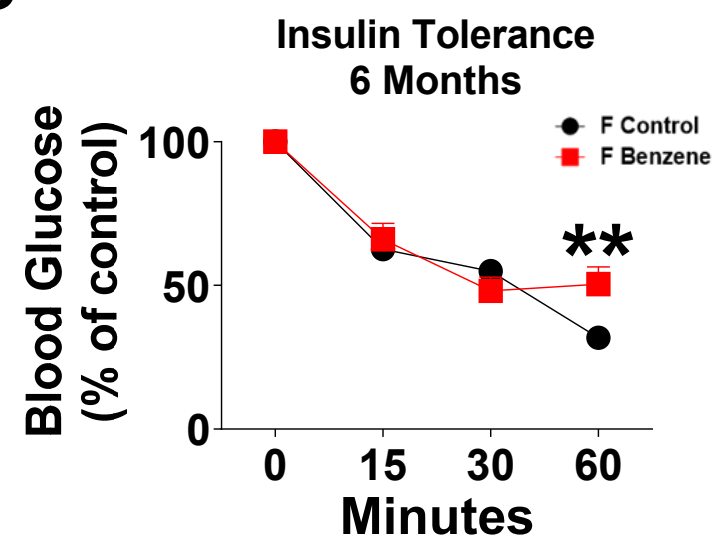


A

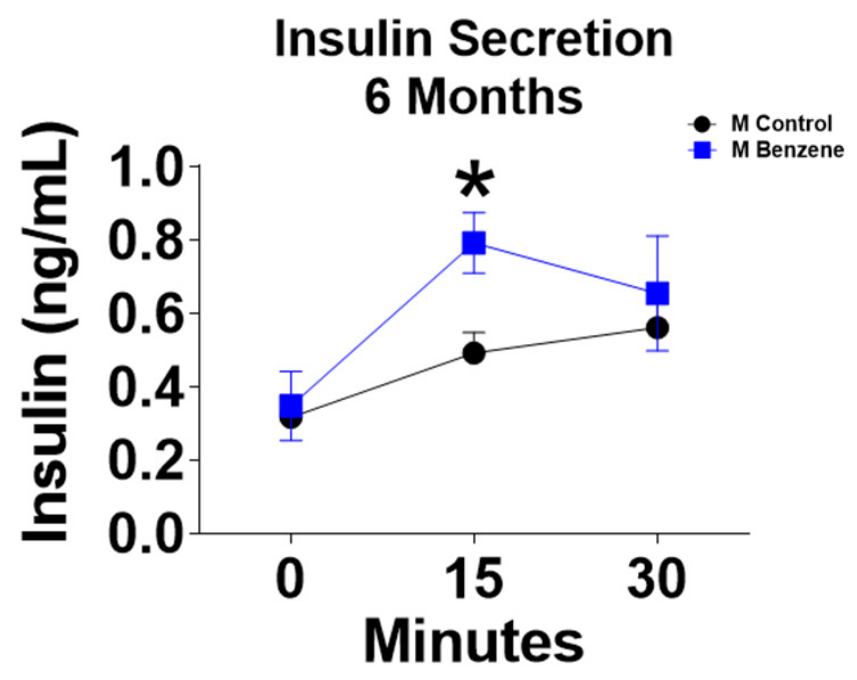

B
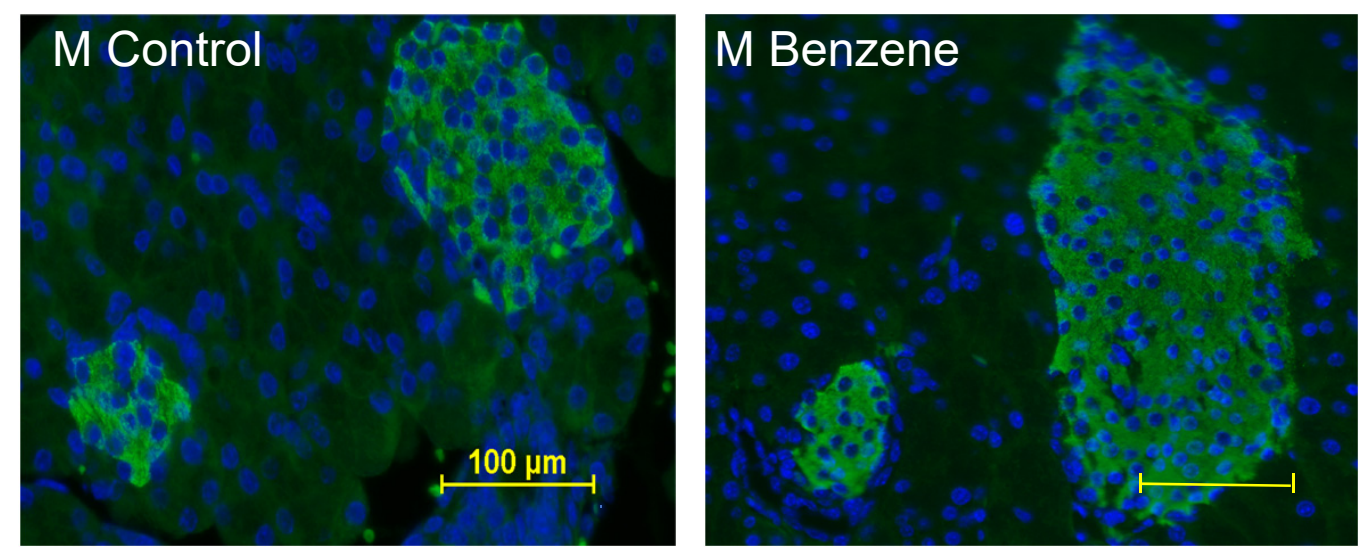

C

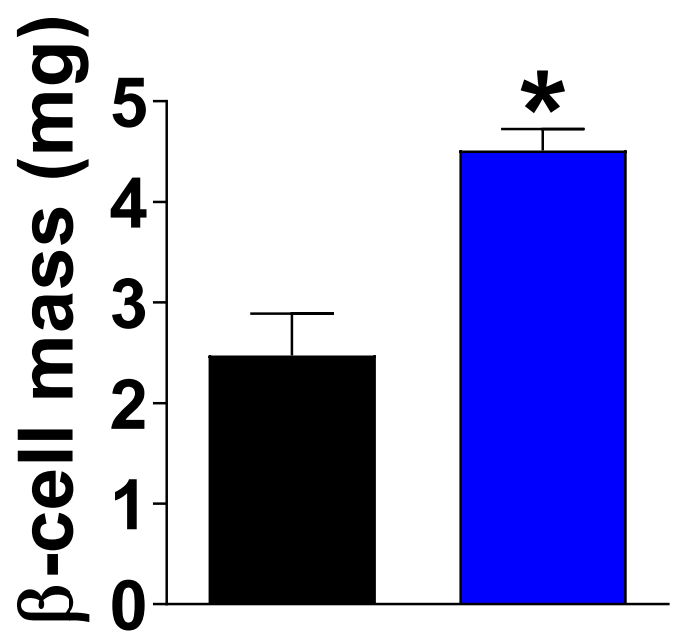




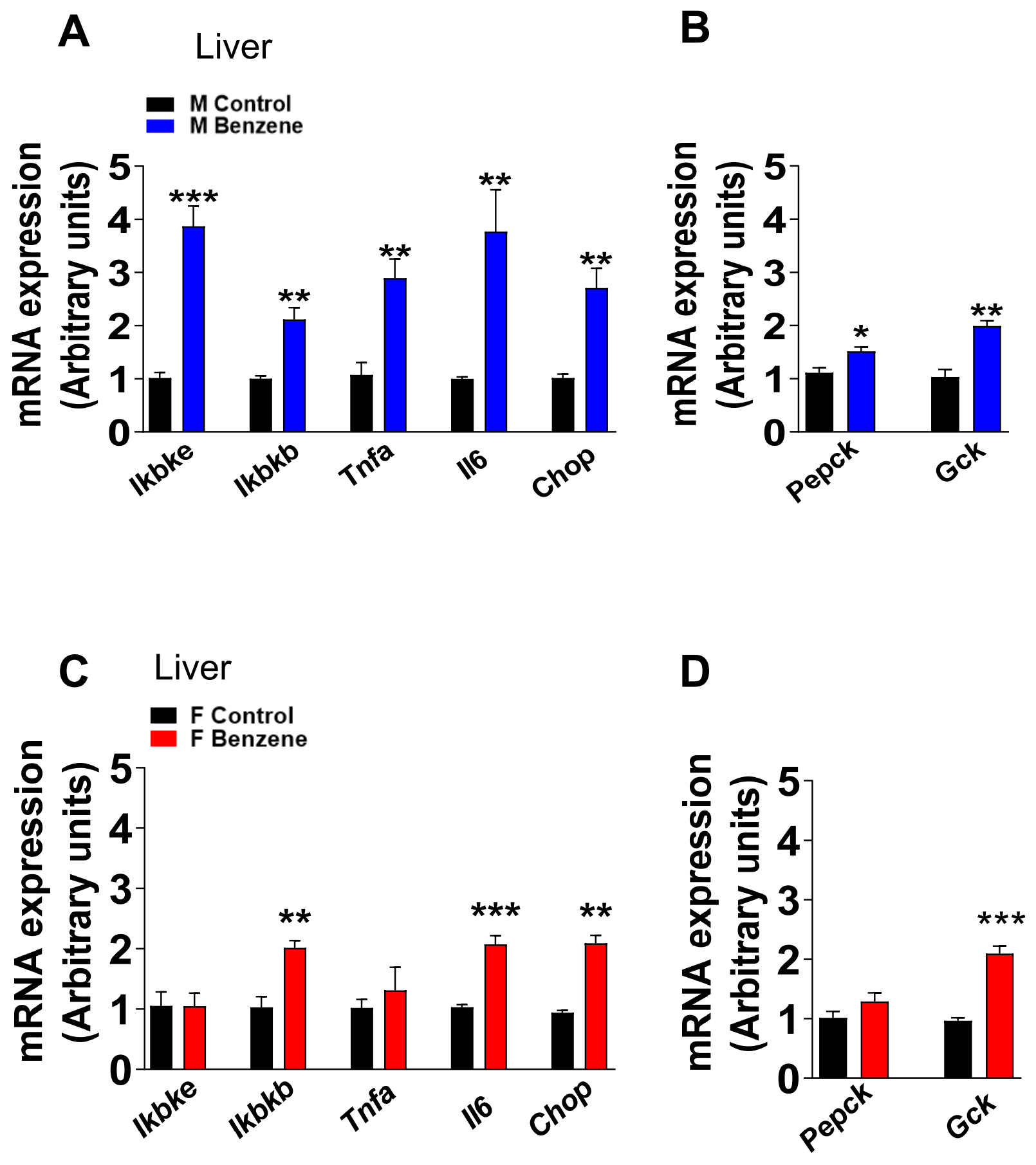


bioRxiv preprint doi: https://doi.org/10.1101/2020.10.12.336313; this version posted October 12, 2020. The copyright holder for this preprint (which was not certified by peer review) is the author/funder, who has granted bioRxiv a license to display the preprint in perpetuity. It is made available under aCC-BY-NC-ND 4.0 International license.

\section{Supplementary Figure 1}

\section{A}
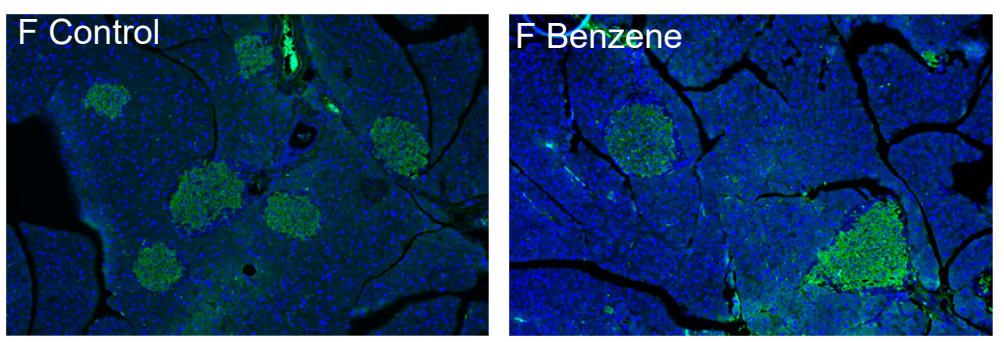

B

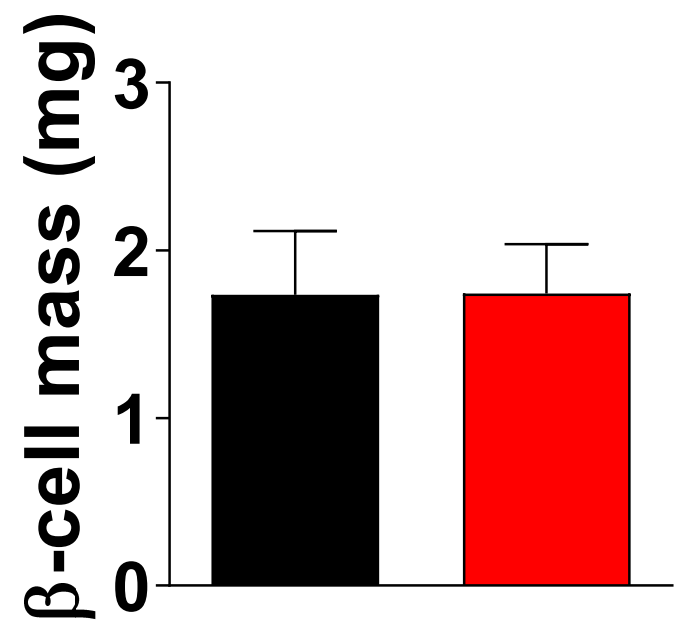


bioRxiv preprint doi: https://doi.org/10.1101/2020.10.12.336313; this version posted October 12, 2020. The copyright holder for this preprint (which was not certified by peer review) is the author/funder, who has granted bioRxiv a license to display the preprint in perpetuity. It is made available under aCC-BY-NC-ND 4.0 International license.

\section{Supplementary Figure 2}

\section{Liver

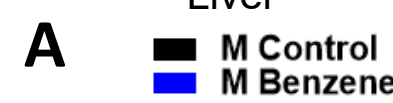

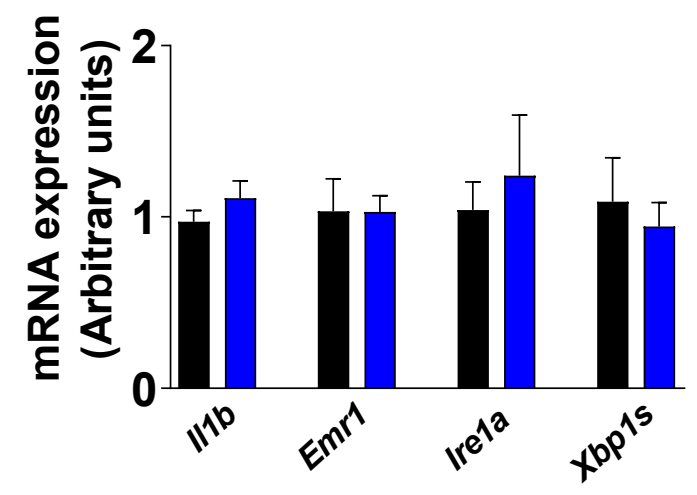
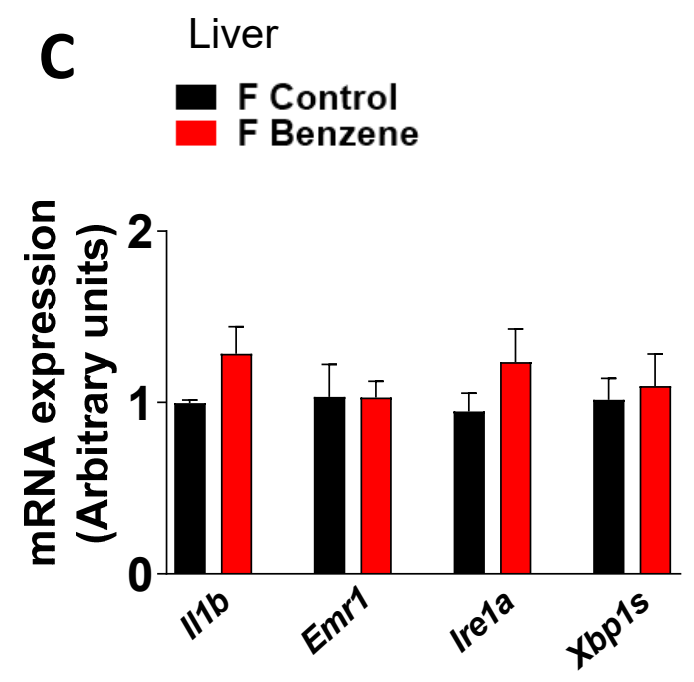

B

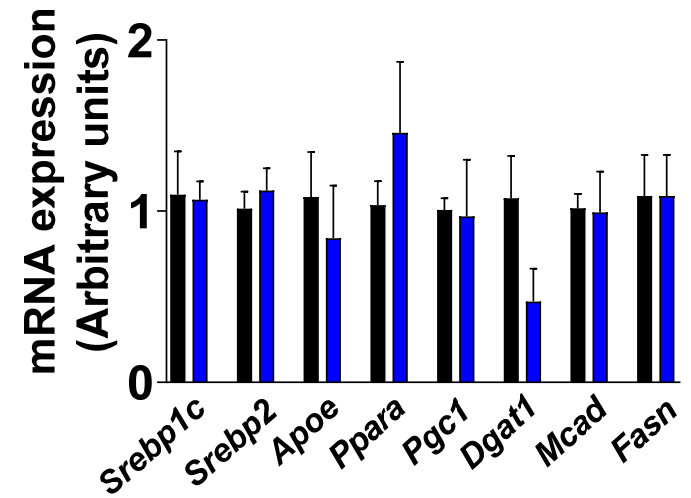

D

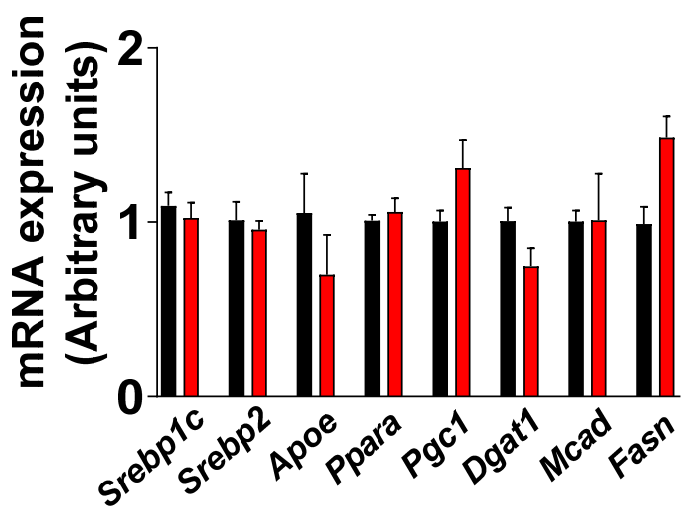




\section{Supplementary Table 1}

\begin{tabular}{lll}
\hline TABLE 1 & & \\
Target & Forward 5'-3' & Reverse 5'-3' \\
Gene & & \\
apoE & acagatcagctcgagtggcaaa & atcttgcgcaggtgtgtggaga \\
B actin & agccatgtacgtagccatcca & tctccggagtccatcacaatg \\
chop & ctgcctttcaccttggagac & cgtttcctggggatgagata \\
dgat1 & tgctacgacgagttcttgag & ctctgccacagcattgagac \\
emr1 & aatcgctgctggttgaatacag & ccaggcaaggaggacagagtt \\
fasn & ggcatcattgggcactcctt & gctgcaagcacagcctctct \\
gck & cggatgcagaaggagatgga & gcatcttcacactggcctctt \\
ikbkb & ggcaccttggatgacctaga & ccatatcctggctgtcacct \\
ikbke & accactaactacctgtggcat & actgcgaatagcttcacgatg \\
il1b & tacaaggagagacaagcaacgaca & gatccacactctccagctgca \\
il6 & ctctgggaaatcgtggaaat & ccagtttggtagcatccatc \\
ire1 $\alpha$ & gccgaagttcagatggaatc & atcagcaaaggccgatga \\
mcad & aacacttactatgcctcgattgca & ccatagcctccgaaaatctgaa \\
pepck & ctcagctggcagcatggggtg & aacagctcctccacgttgacg \\
pgc1 & gcaacatgctcaagccaaac & tgcagttccagagagttcca \\
ppara & gcctgtctgtcgggatgt & ggcttcgtggattctcttg \\
srebp1c & cggaagctgtcggggtag & gttgttgatgagctggagca \\
srebp2 & acagccgcccttcaagtg & tcacaggcattgtggtcagaa \\
tnfa & ccctcacactcagatcatcttct & gctacgacgtgggctacag \\
$x b p 1$ spl & gagtccgcagcaggtg & gtgtcagagtccatggga
\end{tabular}

